\title{
Beyond the classroom: WebCT and learning Modern Hebrew
}

\author{
Yona Gilead \\ University of Sydney
}

The developments of new technologies over the last decades provide some answers to the limited exposure imposed on second/foreign language (L2) learners, who study a target language in an academic setting in countries where that language is not actively used. Not only are such learners restricted in their exposure to the L2 in the formal academic framework, due to the limited face to face learning time, but, more significantly, they lack the exposure to the language's 'real world' as it exists outside the language classroom. They are isolated from the target language's authentic discourse communities and its native speakers. Instead, learners mainly experience the language in its 'modified format' as manifested within the classroom itself.

This paper analyses the rationale for, and the process of, the development of the Modern Hebrew Beginners WebCT site at the University of Sydney as a means of increasing students' exposure to the language and especially enhancing their communication in Hebrew through the use of technologies.

\section{Introduction}

As we enter the twenty first century, second or foreign language (L2) learning and teaching is slowly beginning to adopt many of the technological innovations that have developed not only in our everyday lives, but also and more specifically in the field of education. In his discussion of current changes in information and communication technologies (ICT) and their impact on the field of English language teaching, Warschauer (2000, p. 61) stated that 'information technology is transforming our societies and our lives, and even, eventually, our minds, rather than creating alternate worlds'. His main argument is that in using technology and computers in learning English, students are able to impact on the world they live in (Warschauer, 2000, p. 66). This statement is entirely relevant to Modern Hebrew (MH). It is within such a context, that I wish to discuss the development of the recent MH beginners' WebCT (Web Course Tools) site at the University of Sydney. 


\section{MH program}

Modern Hebrew, one of 15 modern languages taught at the University of Sydney's (USyd) School of Languages and Cultures, is allocated 52 face to face teaching hours per semester. The combination of limited classroom hours and minimal authentic contact with the language (especially at the beginners' levels) demands that language facilitators of the twenty first century initiate new and creative modes of language engagement. These modes should endeavour to increase learners' exposure to the language and especially enhance their communication whilst using that language.

In 2001, the MH program at USyd had fully adopted curricula developed by senior academics from the Rothberg International School, the Hebrew University (HU), Jerusalem, for all its units of study programs (Gilead, 2004). Concurrently, USyd's MH learning and teaching program has been restructured to reflect the HU spiral curriculum which is organised according to six levels of language performance and proficiency. Henceforth USyd's MH program offers a total of 12 units of study, six in the Beginners' strand and six in the Advanced strand. The units of study are structured so that each unit is a continuation of the previous unit. A major in $\mathrm{MH}$ comprises six semesters over three years, and students can enter it at any stage depending on their level of knowledge. Entry is determined by the administration of a placement test developed at the HU.

Specifically, the Beginners' strand follows the program set out in the books Hebrew from Scratch I E II (Chayat, Israeli \& Kobliner 2000; 2001), as well as incorporating the Ma Nishma (Kobliner \& Simons, 1995) language laboratory program into its curricula. Ma Nishma is a language laboratory program for beginner learners of $\mathrm{MH}$. It comprises 67 lessons, which follow and add to the MH L2 learning program set out in the 1990 edition of Hebrew from Scratch (Chayat, Israeli \& Kobliner 1990). Furthermore, being a vital component of the curricula, students are required to complete, on average, one Ma Nishma lesson (which is approximately the equivalent of one hour) per week.

At the time USyd's MH curricula were modified (2001), students were able to access the Ma Nishma program only through the University's META (Multimedia \& Educational Technologies in Arts) Centre's IndividualStudy room. During the first year in which the program was introduced, students quickly adapted to using it and reported both improvements in their language learning and performance, and their satisfaction with this mode of learning. Furthermore, I, the lecturer, witnessed substantial improvement in their language performance and proficiency. 


\section{Reasons for the introduction of the MH WebCT}

In October 2003, the META Centre's Individual-Study room was refurbished. Individual booths that accommodated private and relatively secluded working spaces were removed, leaving the room as an open space (pictures 1 and 2 below respectively).

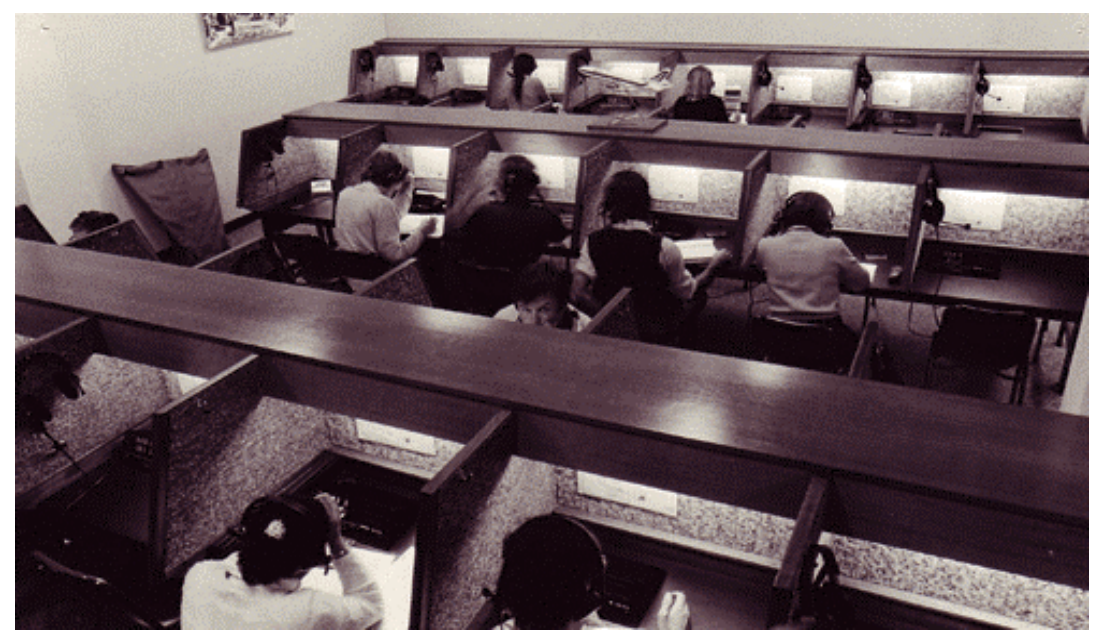

Picture 1: META Centre's Individual-Study room prior to the refurbishment

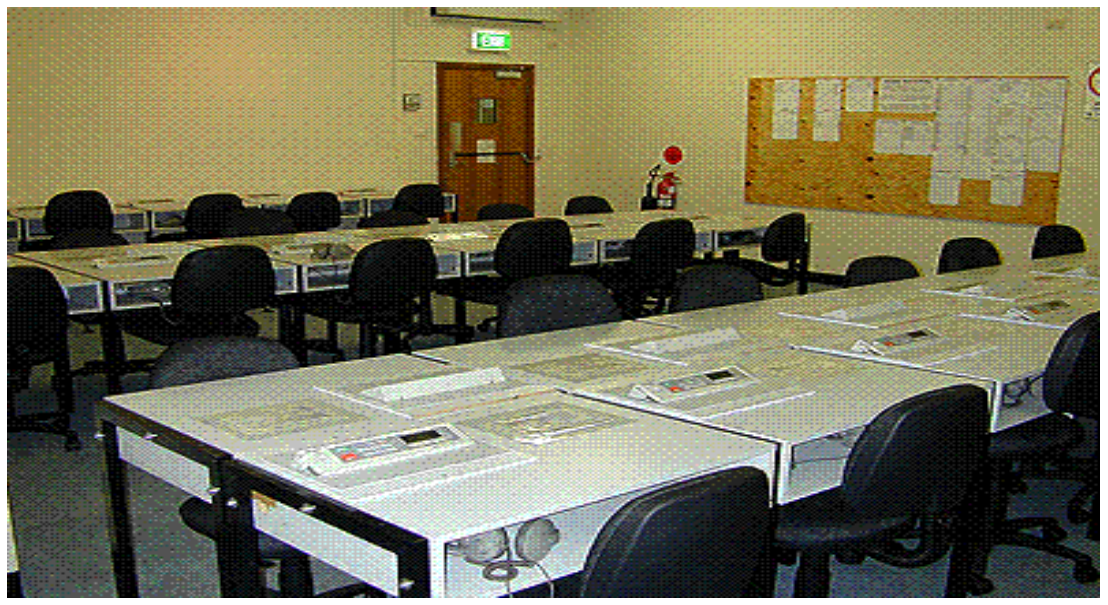

Picture 2: META Centre's Individual-Study room after the refurbishment 
Since those refurbishment modifications were put into place, negative feedback from the students began to filter through. They stated that they were uncomfortable using the Individual-Study room, and hence the $M a$ Nishma program. In the Unit of Study Evaluation carried out at the end of semester II 2003, one student in particular stated: 'I was very unhappy about the new design of the lab. Taking away the booths increased the noise and made it very difficult to listen to the tapes and respond.... Bring back the booths!'). The reasons for their discomfort, which ultimately resulted in greater reduction in accessing the Ma Nishma program, was their perception that they are 'exposed' to other students using the room at the same time. They felt uncomfortable performing many of the oral components of the program. This feeling was heightened by their view that '...only in $\mathrm{MH}$ you need to speak. All the other language students just listen and complete written tasks' (Unit of Study Evaluation, 2003). Thus, the need emerged to consider alternative means of accessing Ma Nishma.

A further consideration, in looking for ways that allowed for alternative means of accessing the program, was due to the fact that use of online learning became more widespread in other courses and programs offered by the University. Additionally, as students became more accustomed to an online mode of delivery, they expressed the desire to have a $\mathrm{MH}$ online component in one format or another. Furthermore, many of the learners are not full time USyd students. Some are part time students whose learning commitments need to be accommodated around demands of employment and other personal commitments (see also Thomas 2003, p. 11). Others are enrolled cross-institutionally, as USyd is the only university in Sydney and NSW that offers MH. Such circumstances make it difficult to attend the on campus classes and further restrict students' ability to use the META Centre, and therefore to access the Ma Nishma program.

All the above reasons led me to consider alternative ways of making the $M a$ Nishma program accessible to students, and especially making it available as an online learning component for MH. In 2004, steps were taken to begin implementing this. Initial consultations with staff at the University's META Centre were carried out. They suggested making the Ma Nishma program available online using WebCT. Copyright approval from HU's publishing house, Academon, was obtained, allowing the program to be installed on WebCT. Thus, in October 2004, half way through Semester II, five (of the total of 67) Ma Nishma lessons were piloted online and henceforth students began accessing the program on their own computers using the University's WebCT online learning facilities.

The very positive feedback received from students for this innovation, encouraged me to arrange to have the entire Ma Nishma program fully installed by the beginning of 2005. As well, I began to consider how I might 
expand online learning by using other facilities and resources available within WebCT.

The University's Flexible Online Learning Team provided a series of workshops covering many of the tools and functions available through WebCT. Additionally, I began reading books and articles that discussed the use of computers and technology in higher education (Curtin, 2002; Dowling, 2003; Thomas, 2003; Littlemore, 2001; Warschauer, 2000; Laurillard, 1993; Laurillard \& Margetson, 1997; Pennington, 2004; Vogel 2001; to name but few). Through the reading and the newly gained operational knowledge in this field, I began contemplating ways of utilising other WebCT resources to further advance students' $\mathrm{MH}$ language learning. Moreover, I came to conceptualise that, in actual fact, I was seeking ways of increasing learner autonomy and self directed learning (Boud, 1981; Chambers \& Davies, 2001; Ramsden, 2003) through the facilitation of new technologies. Thus, learner autonomy and self directed learning encourage students to be more involved in decision making for their own L2 learning process, set their own learning agenda, fulfil their own goals and objectives, and follow their own language learning trajectory (Little, 1990; as well as Boud, 1981; Chambers \& Davies, 2001; Ramsden, 2003). The new technologies offer innovative support for these purposes. Hence, I embraced Littlemore's conclusions about the connection between learner autonomy, self directed learning and new technologies:

Learner autonomy is distinct from self-study in that it implies a capacity for detachment enabling the learner to decide for him/her self how, why, when and where to learn.

Self-directed learning refers to the learning process in which an autonomous learner is involved.

New technologies can be used to encourage different types of independent learning. (Littlemore 2001, p.43)

Furthermore, through this reading and consideration of the possibilities that $W e b C T$ offers, I developed a multi-layered interest in enhancing the $\mathrm{MH}$ site. Firstly, I acknowledged the attraction that ICT (information and communication technology) and CALL (computer assisted language learning) have for today's generation of 'native user' students. This 'native user' generation comprises 'Children who grow up with computers and the Internet [and] will communicate on them with "native-like" fluency' (Warschauer 2000, p. 2; see also Prensky, 2001). Thus, I wanted to add the online component to the $\mathrm{MH}$ program to act as a further motivator for students to engage in their learning processes.

Secondly, I sought to expand the learning experience beyond the twice two-hour weekly on campus classes, the time allocation given by the 
University to all the $\mathrm{MH}$ units of study (Similar time allocations are given to the other languages taught at the University. Furthermore, to the best of my knowledge such is the norm for many, if not most, tertiary L2 learning situations worldwide.) Nevertheless, my strongly held belief is that four hours per week are barely sufficient for successful L2 learning.

Thirdly, I was seeking ways of expanding exposure to the language beyond the on campus classroom learning, for those students who wish to have access to the language in a 'modified learning environment'. I hoped to enable them to continue interacting, with both the language and fellow learners, in a mode suitable to their level of knowledge and expertise.

Fourthly, I wanted to further enhance the community of 'learners of the language' beyond the individual unit of study groups, and to expand this community to include the entire cohort of MH students. Thus, the aim was to bring together all learners from the various UoS (units of study) and to enable them all to communicate with each other.

Finally, I envisaged the possibility of beginning to create a situation whereby learners move from the traditionally sole discourse community (that of the student-students/student-teacher) using the language's modified format, to a situation where learners are encouraged to enter new $\mathrm{MH}$ discourse communities. In this way they can establish connections with students of $\mathrm{MH}$ in other tertiary institutions worldwide, and ultimately communicate with native speakers.

Thus, as a result of looking for ways to make the Ma Nishma program available for use beyond the META Centre, the MH WebCT was conceptualised, and in the process of developing it, new modes for the learning and teaching of the language were introduced. Therefore the main aim of the site has become to facilitate learning and teaching the language, as well as engaging with its various discourse communities, beyond the classroom, through the use of technology.

\section{5}

In Semester I, 2005 the Beginners' Modern Hebrew WebCT' site was launched. This site functions as an umbrella site for all six Beginners strand UoS. The site includes the shared materials used by all six UoS, including the complete Ma Nishma program, and Hebrew from Scratch I $\mathcal{E}$ II CDs, which were developed in the HU. As well, it includes separate icons and folders for each of the six Beginners' UoS. Each UoS site has four files: 'Welcome', which covers all the UoS' general information such as learning skills, learning outcomes, attendance and assessment. 'UoS Outline', which covers the semester's program, 'Grammar \& Syntax', which summarises all the language functions covered by this UoS, and 'What to learn', which lists 
the material students are to be tested on in the upcoming exam, and is updated a week before the upcoming exam. All these six folders were developed locally by USyd's MH coordinator.

As well, the site includes the following icons: 'Students Resources' icon, which includes the folders 'Web Links', 'Grammatical and Syntactical Terminology', 'MH Books in Translation', compiled by the MH coordinator, and the folders 'Library', 'IT Helpdesk', and 'WebCT Helpdesk', all developed by USyd's Flexible Online Learning Team. Finally the site includes the icons/folders 'Discussion Board' and 'Online site Evaluation' (these icons/folders will be further discussed below).

It is important to point out that the Ma Nishma program, and Hebrew from Scratch I \& II CDs that were installed online, remain available in the META Centre. Further, whilst students are required to complete specific $M a$ Nishma lessons, as part of their respective UoS curricula, the mode and location of accessing the program is left to them. Thus, whilst completing the Ma Nishma lessons is compulsory, accessing them via the online mode remains optional.

Additionally, in 2005, students from the Advanced strand were also given access to the site. This was done for two main reasons: we wanted to include them in the $\mathrm{MH}$ community of learners, and thus have them participate in the online discussions. As well, we were in the process of designing an Advanced strand site in the following year, 2006. We anticipate that in the planning of the Advanced site we will utilise, among other considerations, feedback obtained from students that year.

Early in Semester I, 2005, it came to my attention that the format of the 'Discussion Board' that was installed was incapable of accommodating the use of non-Roman characters. In other words, it was not possible to conduct Hebrew written discussions with the installed 'Discussion Board'. Hence, already at that early stage in the Semester, we realised that the 'Discussion Board' was unsuitable for Hebrew discussions, and therefore would not be used for that purpose. However, we did hope that the 'Discussion Board' would be used for English discussions.

During the Semester, USyd's Flexible On-Line Learning Team developed another format of the 'Discussion Board' that is suitable for Hebrew characters. This format was installed and became operational in Semester II, 2005. Hence, in Semester II, we began introducing tasks to be carried out specifically on the Hebrew 'Discussion Board' (Cook 2001; Tomlinson 1997; Hutchinson 1987). It is planned, that once these tasks are successfully piloted, the 'Discussion Board' will become a compulsory requirement of the MH program. 


\section{6}

In Semester I, 2006 the Beginners' site continues to function in the main as it did in 2005. That is, it remains as an umbrella site for all six Beginners strand UoS. In addition, the 'Discussion Board' is formatted to accommodate Hebrew characters, enabling students to conduct written discussions in the target language, though to date writing is only possible from left to right, whilst Hebrew is written from right to left. Thus, the site's previously identified shortcoming was rectified. Other additions to the site are the expansion of the folder 'Web Links', as well as several technical improvements that enable students to gain easier and faster access to the various materials posted online.

Furthermore, teaching staff have been asked to monitor students' use of the site more closely, especially early in the Semester. This is to ensure that all students are accessing the site, whilst at the same time identifying potential 'non-users', who receive further technical support and assistance (see below, 'Tracking students' use of the site').

Additionally, a separate site was developed for the more advanced UoS. This site encapsulates the six Advanced strand UoS. Its structure is in the main very similar to the Beginners' site, but it carries materials applicable for the more advanced learners of the language.

\section{Evaluation}

At the end of Semester I, 2005, as well as at the end of Semester I, 2006 a number of techniques were used to investigate whether the MH Beginners' $W e b C T$ site has been successful in terms of student learning. These included students' online feedback and tracking students' use of the site in 2005 and 2006, and face to face group discussions.

\section{5}

\section{Students' online evaluation feedback}

The MH Beginners' WebCT site was available for students' use from the beginning of Semester I, 2005. An online site evaluation questionnaire, comprising both Likert scale questions and short open ended questions, was posted in week 11 and kept open until week 14 of Semester. The main aim of the evaluation questionnaire was to ascertain the usefulness of this mode of online learning for students. Thus, the questions posted focused on technical, usage, and learning opportunities for students. 
As the site was designed for the Beginners' strand students, the evaluation questionnaire was addressed to them. Once again, even though the students were requested to complete the online evaluation, this was not made compulsory, nor was it followed or tracked by any of the teaching staff during the time between weeks 11 and 14 .

Of the 24 Beginners' strand students, eight responses were received which represents only 33 per cent of this cohort. Whilst this is less than a desirable response, I would like to suggest that this is not unusual, as completing the evaluation was not made compulsory (Hammond and Wiriyapinit report in their paper a less than 50 percent response, 2005, p.8). The eight responses that were received were in the main very positive. Following is the analysis summary of online site evaluation questionnaire for 2005. Students' responses to questions 1-5 and 6-9 and are summarised in the tables below.

Table 1: Summary of Q 1-5

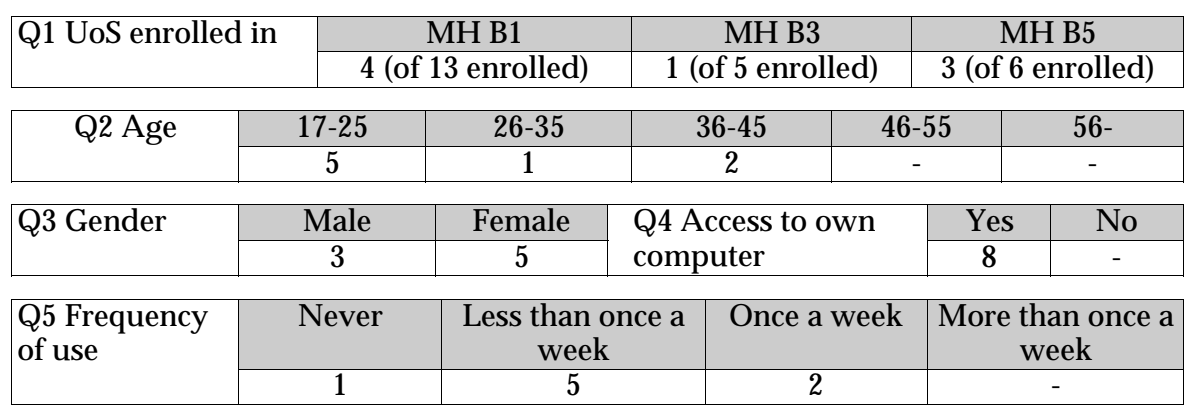

In this context it should be pointed out that the three Beginners' UoS MH B1, B3, and B5 have respectively 14, 13, and $13 \mathrm{Ma}$ Nishma lessons to complete throughout Semester I. Thus, in acknowledging the fact that the students have used the site mainly in order to access the Ma Nishma lessons, accessing it once a week in order to do so would have been sufficient.

In summary, in terms of the site's usefulness, most respondents agree that the online site assisted them in their learning; is a helpful addition to classroom learning; and helps them to learn more efficiently. However, the site only reinforces classroom learning through the Ma Nishma, which is a compulsory component of the respective UoS curricula. As the responses to Q9 indicate, it has largely failed to foster a more general interest in Hebrew language and culture. 
Table 2: Summary of Q 6-9

\begin{tabular}{|l|c|c|c|c|}
\hline \multicolumn{1}{|c|}{ Question } & $\begin{array}{c}\text { Strongly } \\
\text { disagree }\end{array}$ & Disagree & Agree & $\begin{array}{c}\text { Strongly } \\
\text { agree }\end{array}$ \\
\hline Q6. The Online site assists my learning & - & $\begin{array}{c}1 \\
(12.5 \%)\end{array}$ & $\begin{array}{c}5 \\
(62.5 \%)\end{array}$ & $\begin{array}{c}2 \\
(25 \%)\end{array}$ \\
\hline $\begin{array}{l}\text { Q7. The Online site is a helpful addition } \\
\text { to the classroom learning }\end{array}$ & - & 1 & 4 & 3 \\
$(12.5 \%)$ & $(50 \%)$ & $(37.5 \%)$ \\
\hline $\begin{array}{l}\text { Q8. The Online site helps me learn more } \\
\text { efficiently }\end{array}$ & - & $\begin{array}{c}3 \\
(37.5 \%)\end{array}$ & $\begin{array}{c}3 \\
(37.5 \%)\end{array}$ & $\begin{array}{c}2 \\
(25 \%)\end{array}$ \\
\hline $\begin{array}{l}\text { Q9. The Online site helps me develop a } \\
\text { greater interest in Hebrew language and } \\
\text { culture }\end{array}$ & - & 5 & $\begin{array}{c}2 \\
(25 \%)\end{array}$ & $\begin{array}{c}1 \\
(12.5 \%)\end{array}$ \\
\hline
\end{tabular}

In response to the questions 'which program or component do you use the most?' and 'which program or component is most useful to you?' (questions 10 and 11 respectively) seven students named the Ma Nishma program as both most used and most useful. Additionally, two students also stated Hebrew from Scratch, and 'Grammar \& Syntax' respectively as most useful.

Questions 12-14 were open for short answers. In response to Q12, which stated: 'I think the Online site is'..., while all responses were on the whole positive, they also stated that they did not use it very much. Additionally, two respondents stated that the Ma Nishma lessons took a long time to download; one pointed to the inaccessibility of using Hebrew in the 'Discussion Board'; and two thought the 'Web links' were 'great and interesting' (Online site Evaluation, 2005); and one was planning to use it more in the future. In response to Q13, which stated: 'the best thing about the site is'... two stated the flexibility to work from home at one's own pace; two mentioned the Ma Nishma program; one wrote the 'Web links'; and three did not respond. In response to Q14, which stated: 'the Online site can be improved by'..., six did not respond; one suggested to include 'automated email when notices are posted'; and one stated 'the site is unique and a real enhancement to my learning' (Online site Evaluation, 2005).

Finally, no comments were made to Q15, which stated: 'any other comments, suggestions'... From these responses it can be summarised that the site benefited the eight students who responded to the online evaluation.

\section{Tracking students' use of the site}

During the Semester the students' use of the site was not tracked, either by myself or by the respective UoS teaching staff. Only after the semester ended, I commenced studying students' access to the site, using the 
'Student Tracking' function available in WebCT. It should be further noted that for each student the 'Student Tracking' function only indicates which folders were accessed by a student and when. More importantly, even though it is possible to ascertain through this function which students have completed the online site evaluation, it is not possible to link responses to their authors. Therefore, students' responses to the questionnaire remain anonymous and confidential (see also Hammond \& Wiriyapinit, 2005).

Tracking students' usage indicates that the site was used more widely than suggested by the small number of evaluation responses. Thus, it emerged that more students used the site than chose to respond to the online questionnaire. Looking at the patterns of site use, the following emerged.

First year Beginners' UoS (MH B1) had 13 students. One student had not accessed the site at all. Eight students who did not complete the questionnaire had 12, 18, 31, 31, 36, 33, 66 and 81 'hits' respectively. The four students who completed the questionnaire had 12, 37, 46 and 51 'hits' respectively. Second year Beginners' (MH B3) had five students. Four students did not complete the evaluation. Nevertheless they had 5, 6, 27 and 66 'hits' respectively. The one student who did complete the evaluation questionnaire had 39 'hits'. Third year Beginners' (MH B5) had six students. Two students had not accessed the site at all. One student, who did not complete the evaluation, had 21 'hits' and the other three students, who did complete the evaluation, had 32, 44 and 77 'hits' respectively. It is important to emphasise that 'hits' do not equate the number of times a site is accessed. Rather a 'hit' is recorded whenever a different folder or file is accessed. Thus, at any access time or point, a number of folders and/or files can be accessed, each access recorded as another 'hit'.

A closer examination of an individual student's 'history of content page visited' (a function of WebCT's 'Track Students' tool) can shed light on the exact dates when folders and files were accessed. As I am interested in finding out whether the site assisted students in their language learning, rather than analysing individual students access patterns, discussing the latter is beyond the scope of this article. Nevertheless, in considering the fact that the students, who stated they accessed the Ma Nishma program via the site, had on average 30 or more hits, it is fair to suggest that other students who had a similar number of hits also accessed the site. Of the 24 Beginners strand students a total of 15 had more than 27 hits. This suggests that 62 per cent of the Beginners' students used the site. Additionaly, it should be noted that six of the Advanced level students (of a total of 18) also accessed the site recording 5, 11, 11, 13, 15 and 21 hits respectively.

It is further worthwhile noting that the students who did access the site (whether they responded to the online evaluation questionnaire or not) 
were in the main also the ones who eventually received high results in this subject. Thus, there appeared to be a significant correlation between students' accessing of the site and their overall results. However, further research needs to be carried out in order to better understand any correlation between students' site access and their final results. Did the more conscientious students use the online learning mode as part of their overall learning behaviour, or whether, and hence how, the online learning mode impacted positively on learners' language acquisition?

In summary, it emerges that the number of students who did use the site was greater than the number of students who chose to complete the online evaluation questionnaire. It appears that in not making the use of the site compulsory, and by not following and tracking students' use of it throughout the Semester, the decision on whether to use it was completely left to the students' wishes and discretion. Such voluntary access, to both the site and the online evaluation questionnaire, further explains the discrepancy in the information gleaned through the two sources.

\section{6}

In light of the inconsistent findings that emerged in 2005, and a desire to gain further insight into the site's impact on student learning, further research was conducted. Firstly, another evaluation was carried out in 2006, with the online questionnaire modified to allow for longer, more elaborated, open ended answers. Secondly, to include another method of data collection and thus reach further triangulation (Hammond \& Wiriyapinit, 2005), a WebCT focus group discussion was held.

As in 2005, the 2006 online site evaluation questionnaire was posted in week 11 and kept open until week 14. The same questionnaire was posted on both the Beginners' and the Advanced sites. However, students were actively reminded of the importance of completing the questionnaire. This was done via posting messages on the 'Discussion Board', sending reminder emails, and announcing by teaching staff in classes. During the three weeks the online evaluation was open, student responsiveness (that is whether they completed the evaluation rather than the content of their responses) was tracked.

\section{Students' online evaluation feedback}

This year, once again, the main aim of the evaluation was to ascertain the usefulness of the online learning mode. Of the 29 Beginners strand students, 17 responses were received. That represents 59 per cent of the cohort, an increase in response rate of close to 20 percent from the previous year. Following is the analysis summary of the online site evaluation 
questionnaire for 2006. Students' responses to questions 1-5, and 6-8 and 11 are summarised in the tables below.

Looking at the significant shift in responses from 2005 to 2006, there has been a substantial increase in students' positive reporting regarding the WebCT site's effect on their learning. There was an increase in the accumulated 'Agree' and 'Strongly Agree' categories on all four questions, as well as a decline in the 'Disagree' category as shown respectively in Table 2 (above) and Table 4 (below).

Table 3: Summary of Q 1-5

\begin{tabular}{|c|c|c|c|c|c|c|c|c|}
\hline \multicolumn{2}{|c|}{ Q1 UoS enrolled in } & \multicolumn{2}{|c|}{ MH B1 } & \multicolumn{2}{|c|}{ MH 3} & \multicolumn{3}{|c|}{ MH 5} \\
\hline \multirow{2}{*}{\multicolumn{2}{|c|}{ Q2 Age }} & \multirow{2}{*}{$\frac{17-25}{13}$} & $26-35$ & & $36-45$ & \multicolumn{2}{|c|}{$46-55$} & $56-$ \\
\hline & & & 2 & & 1 & & & 1 \\
\hline \multirow[t]{2}{*}{ Q3 Gender } & Male & Female & Not stated & \multirow{2}{*}{\multicolumn{3}{|c|}{$\begin{array}{l}\text { Q4 Access to own } \\
\text { computer }\end{array}$}} & Yes & No \\
\hline & 6 & 10 & 1 & & & & 15 & 2 \\
\hline \multirow{2}{*}{\multicolumn{2}{|c|}{$\begin{array}{l}\text { Q5 Frequency of } \\
\text { use }\end{array}$}} & Never & \multirow{2}{*}{\multicolumn{2}{|c|}{$\begin{array}{c}\begin{array}{c}\text { Less than once a } \\
\text { week }\end{array} \\
3\end{array}$}} & \multicolumn{2}{|c|}{ Once a week } & \multicolumn{2}{|c|}{$\begin{array}{l}\text { More than once } \\
\text { a week }\end{array}$} \\
\hline & & & & & & & & \\
\hline
\end{tabular}

Table 4: Summary of Q 6, 7, 8, 11

\begin{tabular}{|l|c|c|c|c|}
\hline Question & $\begin{array}{c}\text { Strongly } \\
\text { disagree }\end{array}$ & Disagree & Agree & $\begin{array}{c}\text { Strongly } \\
\text { agree }\end{array}$ \\
\hline Q6. The Online site assists my learning & - & $1(6 \%)$ & $9(53 \%)$ & $7(41 \%)$ \\
\hline $\begin{array}{l}\text { Q7. The Online site is a helpful addition } \\
\text { to the classroom learning }\end{array}$ & - & $\begin{array}{c}1 \\
(6 \%)\end{array}$ & $\begin{array}{c}8 \\
(47 \%)\end{array}$ & $\begin{array}{c}8 \\
(47 \%)\end{array}$ \\
\hline $\begin{array}{l}\text { Q8. The Online site helps me learn more } \\
\text { efficiently }\end{array}$ & - & $\begin{array}{c}2 \\
(12 \%)\end{array}$ & $\begin{array}{c}11 \\
(65 \%)\end{array}$ & $\begin{array}{c}4 \\
23 \%)\end{array}$ \\
\hline $\begin{array}{l}\text { Q11. The Online site helps me develop a } \\
\text { greater interest in Hebrew language and } \\
\text { culture }\end{array}$ & - & $\begin{array}{c}3 \\
(18 \%)\end{array}$ & $\begin{array}{c}13 \\
(76 \%)\end{array}$ & $\begin{array}{c}1 \\
(6 \%)\end{array}$ \\
\hline
\end{tabular}

Additionally, questions Q6B, 7B, 8B, and 11B respectively, were open for short answers. In response to $\mathrm{Q} 6 \mathrm{~B}$ ' the online site assists/does not assist my learning', most respondents commented on the site's advantage of allowing access to the Ma Nishma and Hebrew from Scratch programs from home. They stated that the site enabled them to 'listen to Hebrew spoken properly outside of the class', and 'gives us the option of more strongly immersing ourselves in the language' (Online site Evaluation, 2006). Several students reported that it reinforces the grammar and language structures taught in class and others commented that it assisted them to improve their pronunciation by recording themselves speaking. Other positive comments included the usefulness of the 'Discussion Board': '[it] 
helps me to talk to others about the course as well as find out news', and 'questions can be asked and answered on the online chat' (Online site Evaluation, 2006). On the other hand, other comments were: 'I don't feel the need to use the site', and 'I don't have a computer and since I don't enjoy using the university's computer I am not disposed to take advantage of the online tools' (Online site Evaluation, 2006).

In response to Q7B' the online site is a helpful/unhelpful addition to classroom learning', comments that suggested that the site is a helpful addition to classroom learning were '[it] allows you to do follow up work outside the classroom', 'the online site complements, reinforces and adds to what we learn in class', and 'it provides an opportunity for off site interaction between the students' (Online site Evaluation, 2006). On the other hand there were also comments that argued that the online site was not a helpful addition to classroom learning. They were: 'a lot of what we learn in class can't really be taught over the internet', and 'I found it to be quite separate to the topics we were learning in class - sometimes it was good and sometimes distracting' (Online site Evaluation, 2006).

In response to Q8B 'the online site helps/does not help me to learn more efficiently', most responses again pointed to the fact that the site's contribution to more efficient learning was due to making the Ma Nishma and Hebrew from Scratch available online, and thus resulting in the outcomes discussed above. As one student put it: 'whilst the online site can be beneficial, I suggest it is incidentally so rather than necessarily' (Online site Evaluation, 2006). However, other students pointed to the availability of the 'Discussion Board': 'we have the opportunity to ask each other questions and get help faster than having to wait until the next class - that helped some people a lot' (Online site Evaluation, 2006).

In response to $\mathrm{Q} 11 \mathrm{~B}$ 'the online site helps/does not help me develop a greater interest in Hebrew language and culture', most respondents commented that the site helps develop interest in the Hebrew language. However, they do not think it is helpful in developing a greater interest in Hebrew culture. The main reason was that not many materials are available.

In response to questions 9 'which program or component do you use the most?' and 9B, 'briefly describe why', ten students named the Ma Nishma program; two named Hebrew from Scratch; two named the 'Grammar \& Syntax' folder contained in the 'UoS' icon; and three respondents named the 'Discussion Board'. As to questions 10, 'which program or component is most useful to you?' and 10B, 'briefly describe why', twelve students stated Ma Nishma; three stated Hebrew from Scratch, and one the 'Grammar \& Syntax' contained in the 'UoS' icon. Once again, the availability of 
accessing Ma Nishma and Hebrew from Scratch from home dominated the responses. In addition, several respondents emphasised the value of out of class communication through posting messages on the 'Discussion Board'.

Finally, Q 12-15 inquired about the students' overall opinion of the WebCT site, as well as of potential future improvements. On the whole responses were very positive. They reiterated the views regarding the site's reinforcement of classroom learning, especially relating to Hebrew pronunciation; and the site's accessibility and flexibility. Most importantly, the site's function as a space for both the Ma Nishma and Hebrew from Scratch programs; and the 'Discussion Board's function as a forum for out of class communication was highlighted. 'The site is a great adjunct to my learning', 'a great complement to the class', and 'helpful in making us treat Hebrew like another subject at uni' (Online site Evaluation, 2006). Again, there were some less enthusiastic comments, one stating that the site is 'potentially beneficial... but overall not indispensable', another branding it as 'pretty useless' (Online site Evaluation, 2006).

In reference to future developments, the suggestions were: adding a larger cultural component; adding more interesting web links; further improving the site by developing more responsive controls to the Ma Nishma and Hebrew from Scratch programs that will improve zooming to specific texts, as well as rewinding and fast forwarding; and finally adding compulsory Hebrew tasks and postings on the 'Discussion Board'.

\section{Tracking students' use of the site}

During the Semester the students' usage of the site was tracked. This was done more closely early in the Semester and again once the Online Evaluation questionnaire was opened. Looking at the patterns of site use, the following emerges. First year Beginners' UoS (MH B1) had 17 students. All had accessed the site. Five students who did not complete the questionnaire had 82, 124, 130, 58 and 67 'hits' respectively. The twelve students who completed the Evaluation had 157, 216, 183, 76, 191, 157, 332, 148, 256, 575, 388 and 154 'hits' respectively. Second year Beginners' (MH3) had seven students. The only student to complete the Evaluation questionnaire recorded 227 'hits'. The other students' recorded 7, 49, 135, 112, 91 and 40 'hits' respectively. Once again this strongly suggests that they used the site despite not completing the Evaluation questionnaire. The third year Beginners' (MH 5) had five students. The one student who did not complete the Evaluation questionnaire still recorded 91 'hits'. The other four recorded 139, 203, 271 and 107 'hits' respectively. These numbers clearly reflect that all Beginners strand students used the site. Furthermore, the significant rise in the number of 'hits' recorded by all students in the 
cohort is another indication of the site's increased usage. Finally, this year there was no clear correlation between students' final results and their usage of the WebCT site.

\section{WebCT focus group discussion}

The focus group discussion was held in the first week of Semester II, 2006. The discussion was carried out with two main objectives in mind. The first objective was to reach further triangulation in regards to students' perspectives, so that the Online Evaluation questionnaire is not the only source of information. The second aim was to try and probe further into the actual effects that the online MH WebCT site had on the students' language learning behaviour.

Students' were advised that language learning behaviour refers to all that they do in learning the language: both in class and in self study, and internally as well as externally. Additionally, they were provided with the following definition:

\footnotetext{
The term language learning behaviour is used as an umbrella term that encapsulates all that the learners do, both externally and internally in the course of learning the second/foreign language. Thus, learning behaviour refers to the discursive interaction in the classroom, and the learning processes both in the classroom setting and in self study. (Gilead, 2005 unpublished)
}

Nine students, all previously enrolled in MH B1 participated in the forum. All nine students reported having access to their own computer. Four were male and five were female. Six were in the 17-25-age bracket; two were in the 26-35 bracket; and one in the 36-45 bracket. With regards to frequency of accessing the site, four accessed it less than once a week; one once a week; and four more than once a week.

The most interesting and insightful responses emerged during the open discussion forum. Firstly the three students from the older age brackets (26$35,36-45)$ stated that they found it difficult (both mentally and technically) to adapt to the online learning mode. However, they did see the value in such a mode and have undertaken upon themselves to try and increase their online learning. Of the four students who accessed the site less frequently, two were from the older age bracket (who were not used to studying with computers), and one (from the 17-25 age bracket) reported that before exams his usage of the site increased. The four students, who used the site more frequently, reported doing so between once and three times per week. 
The Ma Nishma program was consistently reported as both the program mostly used and most useful (eight and six responses respectively). Undoubtedly the reason for that is $M a$ Nishma's compulsory nature (even though students have the option of accessing the program through the META Centre, see p. 5). In the open discussion, all participants clearly stated that they found the Ma Nishma particularly useful for drilling and pronunciation. Furthermore, several students commented that it enabled them to further revise and clarify to themselves at home, materials covered in class. One comment that received general agreement, was that the importance of Ma Nishma is that it answers some questions that people might not have time to ask in class, or be too shy, or afraid to appear stupid' (WebCT focus group discussion, 2006). This home revision mode increased and was particularly useful prior to exams.

Moreover, most students were adamant that had the Ma Nishma not been available online, but only at the META Centre, they would have not completed that requirement of the curriculum. At the same time several students commented that for a number of the Ma Nishma lessons, audibility was poor, a fact that made listening and drilling very difficult and frustrating.

In addition to the Ma Nishma, the other programs and components that emerged as being useful were Hebrew from Scratch, the 'Discussion Board' and the 'Grammar \& Syntax' file that is located in the 'UoS' icon. Several students commented that they could perceive an increase in these components' usefulness as the learning progresses.

The final topic discussed in the forum was the effect the WebCT site has on their learning behaviour. Again, most reported that the site's most significant effect was that it made the Ma Nishma and the Hebrew from Scratch programs more accessible. In other words, having these programs available online and thus accessible at any time and place, resulted in the fact that they were used by the students as was required by the course. This usage in turn enabled most students to develop their aural and oral skills; to practice their spoken Hebrew; to drill vocabulary and language patterns, as well as to revise texts. As a result their language learning, especially in the area of pronunciation and oral communication, was more effective. Furthermore, there was a consensus among the group discussion participants that had the programs not been available at the students' chosen time and location, they would have used them less.

It is worth pointing out that even those students who were less comfortable with online learning agreed that completing the audio tasks was worthwhile. Of these, one student reported 'Ma Nishma and the online learning wasn't really that effective for my learning. I find that I learn 
better when I come to class and interact with other people'; another (from the older age bracket) reported that having the computer component possibly dampened my enthusiasm just a little... the whole ritual of sitting down and doing things online is so unnatural to me... I would have much preferred to find some alternative way of doing it [Ma Nishma]. A third student (again from the older age bracket) went so far as to admit that if I was unable to access the Ma Nishma from home, I would have dropped it, forgotten about it and not done it and failed' (WebCT focus group discussion, 2006).

In contrast to these views, another student stated 'I have an audio memory so for me listening to things is the way that I learn. I don't think that I would have done nearly as well had I not been able to hear things from the textbook' (WebCT focus group discussion, 2006). This is one of the students who reported accessing the site three times a week.

A number of students commented on their satisfaction with the 'Discussion Board' and reported on its value as a channel for communicating with other students and especially as a helpful tool or means of asking questions and getting help between lessons.

\section{Self reflection}

Since 2004, I have spent considerable time and effort developing the $\mathrm{MH}$ WebCT sites, initially the Beginners and later the Advanced strand site. As discussed above, the development process commenced as a result of students' requests to find alternative modes of accessing the Ma Nishma program. It followed the positive response to the initial installation of the first five Ma Nishma lessons in late 2004 (in which I was greatly assisted by the META Centre's staff members), and in late 2004 and early 2005 most of the development work was carried out. During that period I gradually increased my knowledge, both theoretical and operational, regarding online learning in general, and WebCT in particular. The length of time spent was mainly due to the fact that it was the first time I had designed an online learning mode. Furthermore, as the impetus for the development of the Beginners site came as a result of students' request rather than my own pedagogical philosophy, I was unsure of the educational purposes I wanted the site to serve.

Following the completion of a series of workshops on online learning conducted by the University, alongside reading in this area, and followed by much self contemplation, I decided to include in the site as many learning materials as possible. Even though I suspected that the Ma Nishma program would be the component mostly used, I was greatly interested in 
beginning to develop means for students to increase their contact with the language beyond the four weekly face to face contact hours.

Additionally, I wanted to facilitate ways for those students who wanted to, to be able to enter the language's authentic discourse communities and come into contact with its native speakers if they wished to take advantage of this opportunity. Moreover, I hypothesised that the online learning mode will continue to develop further with time. As the students, the other $\mathrm{MH}$ teaching staff, and myself (as the site designer) become more accustomed to this type of learning and teaching mode, the sites will be better and more frequently utilised.

As a result of the knowledge gained in 2005, a number of modifications were implemented throughout Semester II, 2005, and in preparing both sites for the 2006 academic year. The main change was the adjustment made to the 'Discussion Board' to allow Hebrew writing. Additionally, students' use of the Beginners strand site was monitored closely in Semester I, 2006. This was particularly important, as we had found out that technical difficulties in accessing the site were a major factor impacting on students' usage of the site. Furthermore, a greater effort was made to ensure that the teaching staff were more actively involved in monitoring students' online participation (p. 5).

From a pedagogical perspective, the most interesting and important information that emerged for me from the 2006 cohort is how the site affects individual learners differently. Many students (especially from the 17-25 bracket) found the site a valuable and effective addition to classroom learning, and therefore used it extensively. Other students found it had little effect on their language learning, while others again, expressed discomfort with and dislike for this mode of learning. These views reflect students' idiosyncratic ways of learning, which in turn, implies that different modes of learning must be catered for and facilitated. Therefore, it points out the importance of the WebCT site as an integral component of the MH curricula.

\section{Conclusion}

I think that it is fair to conclude that the MH Beginner strand WebCT site is successful for a number of reasons. Primarily, it is successful in enabling students to access the Ma Nishma and Hebrew from Scratch programs from their own computers and complete the programs' aural and oral tasks in the privacy and comfort of their own learning environment. As shown above, the feedback collected, especially from the 2006 cohort, both from the Online Evaluation questionnaire and the WebCT focus group discussion, indicates that students both used the WebCT site and reported 
that it contributed to their language learning. The most significant contribution appears to be in the area of pronunciation and oral communication. Additionally, the 'Discussion Board' emerged as a vehicle for out of class communication. Many students perceive this space as a useful and convenient forum for asking questions and clarifying issues and difficulties.

Other benefits are firstly that I, the $\mathrm{MH}$ program coordinator, together with the other teaching staff, have become more open to the idea that the rapidly developing and changing technologies, and the new generation of 'native user' students (p. 4) who grew up with these technologies as well as with the ease of using them in their daily lives, requires us as educators to initiate and incorporate new modes of learning and teaching into our classroom. Specifically in relation to the MH WebCT sites, I have become aware of both the need for including, and the possibilities within, learning modes that exist beyond the classroom. Secondly, the benefits of encouraging the facilitation of autonomous learning of the language has in general crystallised in my mind, and the benefits of using WebCT's many tools, which have the potential to increase learners' engagement with the language and its discourse communities, specifically have been highlighted.

With the success of the Beginners strand site, an Advanced strand site was launched in 2006. Currently the site's structure is similar to the Beginners strand site, however it contains materials suited to the more advanced knowledge of Hebrew. Even though the site was used in Semester I, 2006, it was done so less extensively than the Beginner strand site. Furthermore, only a small number of the 12 enrolled students completed the Online Evaluation questionnaire. As yet, no information is available as to why more students did not complete the questionnaire. This might suggest two possibilities. Firstly, it could be argued that the students did not perceive the site as a useful learning space, which in turn suggests that more work needs to be carried out in order to make the site more useful to them. Secondly, there is the possibility that the teaching staff were not sufficiently involved in encouraging students' online participation, or in actively monitoring it. Based on the experience of the Beginners strand site, where the response rate to the Online Evaluation questionnaire increased from 2005 to 2006 due to significant teacher involvement (see p. 9), I would like to suggest the latter possibility. Hammond and Wiriyapinit's finding (2005, pp. 6-7), concerning the connection between tutors' involvement and students' online activity further supports this option. Thus, they report that in their case study 'Message analysis showed that the most active groups tended to have the most active tutor.' 
Nevertheless, from designing, pedagogical and management perspectives there are a number of further implementations that need to be carried out in order to enhance both the sites and their usage. Currently, several technical improvements have been completed. Firstly, it has been established that by using Real Player application it is possible to operate more accurately a computer's rewind and fast forward controls. This will hopefully enable students to better utilise the Ma Nishma and Hebrew from Scratch programs (see p. 11). Secondly, a number of tasks are in the process of being designed specifically for posting on the 'Discussion Board'. This will require students to access the site and utilise this online tool.

Thirdly, the need for teaching staff's ongoing involvement and monitoring of students' online participation is clear. As previously discussed, students' online activity correlated significantly with teaching staff's involvement. This can be seen both by the larger number of the 2006 Beginners strand cohort who responded to the online questionnaire, and by the increased number of 'hits' recorded by this cohort (p. 11). Furthermore, within this cohort, the two UoS that students recorded most 'hits', and had most responses to the Online site Evaluation (70 percent for $\mathrm{MH} \mathrm{B1}$, and 80 percent for MH5), were taught by the program coordinator who testifies to regular tracking of students' activity as well as weekly reminders to complete the Evaluation questionnaire once it was opened. These classes' significant response rate stands in contrast to the fewer 'hits' and 14 percent response received in MH3. Thus, the teaching staff's close and active involvement in the WebCT site is essential.

Finally, further research projects are planned in order to find answers to a number of questions raised in this article. The questions revolve around the impact and effects the MH WebCT sites have on students' language learning behaviour. They are: the relation between students' use of WebCT and their language learning; the impact of online learning on students' language development; different approaches to online learning that stem from learners' age and attitudes towards learning with new technologies; and the development of specific Hebrew language tasks for online learning.

\section{Acknowledgements}

The author would like to thank Suzanne Rutland and Jenny Hammond.

\section{References}

Boud, D. (1981). Developing student autonomy in learning. London and New York: Kogan Page and Nichols.

Chambers, A. \& Davies, G. (Eds) (2001). ICT and language learning: A European perspective. Lisse, The Netherlands: Swets \& Zeitlinger. 
Chayat, S., Israeli, S. \& Kobliner, H. (2000). Hebrew from Scratch (Vol. I). Jerusalem: Academon, the Hebrew University Students' Printing and Publishing House.

Chayat, S., Israeli, S. \& Kobliner, H. (2001). Hebrew from Scratch (Vol. II). Jerusalem: Academon, the Hebrew University Students' Printing and Publishing House.

Cook, V. J. (2001). Second language learning and language teaching (3rd ed.). London and New York: Arnold and Oxford University Press.

Curtin, J. (2002). WebCT and online tutorials: New possibilities for student interaction. Australian Journal of Educational Technology, 18(1), 110-126. http://www.ascilite.org.au/ajet/ajet18/curtin.html

Dowling, C. (2003). New educational technologies: Do they improve learning? On the Horizon, 11(1), 14-16.

Gilead, Y. (2004). Revival strategies: Modern Hebrew, the University of Sydney. In G. Wigglesworth (Ed), Proceedings of the Marking Our Difference Conference 2003 (pp. 54-66). Melbourne: School of Languages, University of Melbourne.

Hammond, M. \& Wiriyapinit, M. (2005). Learning through online discussion: A case of triangulation in research. Australasian Journal of Educational Technology, 21(3), 283-302. http://www.ascilite.org.au/ajet/ajet21/hammond.html

Hutchinson, T. (1987). What's underneath? An interactive view of materials evaluation. In L. E. Sheldon (Ed), ELT textbooks and materials: Problems in evaluation and development (pp. 37-44). London: Modern English Publications in association with The British Council.

Kobliner, H., \& Simons, E. (1995). Ma Nishma. Jerusalem: Academon, the Hebrew University Students' Printing and Publishing House.

Laurillard, D. (1993). Rethinking university teaching: A framework for the effective use of educational technology. London; New York: Routledge.

Laurillard, D., Margetson, D. \& Griffith Institute for Higher Education (1997). Introducing a flexible learning methodology: discussion paper. Nathan, Qld: Griffith University, Griffith Institute for Higher Education.

Little, D. G. (1991). Learner autonomy. Dublin: Authentik.

Littlemore, J. (2001). Learner Autonomy, Self-Instruction and New Technologies in Language Learning: Current Theory and Practice in Higher Education in Europe. In A. Chambers \& G. Davies (Eds), ICT and language learning: A European perspective (pp. 39-60). Lisse: Swets \& Zeitlinger Publishers.

Pennington, M. C. (2004). Cycles of innovation in the adoption of information technology: a view for language teaching. Computer Assisted Language Learning, 17(1), 7-33.

Prensky, M. (2001). Digital natives, digital immigrants. On the Horizon, 9(5). [viewed July 2005, verified 22 Dec 2005] http:/ / www.marcprensky.com/writing/default.asp 
Prensky, M. (2001). Do they really think differently (Digital natives, digital immigrants, part II). On the Horizon, 9(6). [viewed July 2005, verified 22 December 2005] http:/ / www.marcprensky.com/writing/default.asp

Ramsden, P. (2003). Learning to teach in higher education (2nd ed.). London; New York: Routledge Falmer.

Thomas, P. (2003). Avoiding the 'virtual': building learning communities in offcampus language learning. Australian Review of Applied Linguistics, Series S(17), 111-124.

Tomlinson, B. (1997). Materials development in language teaching. Cambridge; New York: Cambridge University Press.

Vogel, T. (2001). Learning out of control: Some thoughts on the World Wide Web in learning and Teaching Foreign Languages. In ICT and language learning, $a$ European perspective (pp. 133-145). Lisse: Swets \& Zeitlinger Publishers.

Warschauer, M. (2000). The death of cyberspace and the rebirth of CALL. English Teachers' Journal, 53, 61-68.

Ms Yona Gilead is the Modern Hebrew Program Coordinator and Associate Lecturer in the Department of Hebrew, Biblical and Jewish Studies, School of Languages and Cultures, the University of Sydney, Sydney NSW 2006, Australia. Email: yona.gilead@arts.usyd.edu.au 